\title{
Inflammatory myofibroblastic tumour of the bladder: Case report and review of the literature
}

\author{
Li Wei, MD; ${ }^{*}$ Liang Jianbo, MD; ${ }^{*}$ Wei Qiang, MD; ${ }^{\dagger}$ Yu Hai, MD; ${ }^{*}$ Lan Zhixiang, $M D^{*}$
}

"Department of Urology, The People's Hospital of Guangxi Zhuang, Autonomous Region, Nanning, China; 'Department of Pathology, The People's Hospital of Guangxi Zhuang, Autonomous Region, Nanning, China

Cite as: Can Urol Assoc J 2013;7:E237-40. http://dx.doi.org/10.5489/cuai.544

\section{Abstract}

Inflammatory myofibroblastic tumour (IMT) is a rare tumour with malignant potential, and has been described in many major organs. However, bladder location is very uncommon. We report the case of a 23-year-old woman who presented with painless gross hematuria for 2 weeks. Contrast-enhanced computed tomography revealed a bladder tumour. The patient underwent an open partial cystectomy and the final pathologic diagnosis was IMT of bladder. Typical IMTs can be locally aggressive, therefore close follow-up is necessary.

\section{Introduction}

Inflammatory myofibroblastic tumour (IMT) is a rare tumor with malignant potential; it is also known as inflammatory pseudotumour. IMT has been described in many major organs, including lungs, ${ }^{1}$ liver $^{2}$ and skin. ${ }^{3}$ In the genitourinary system, IMT likely starts in the bladder, but the lesion has also been reported in the kidneys, prostate, ureter ${ }^{4}$ and epididymis. ${ }^{5}$

Roth reported the first case of IMT of the bladder in $1980 .{ }^{6}$ In the past 10 years, more than 20 cases of bladder of IMT have been documented. The largest clinicopathologic study was reported by American pathologists in 2006. This study included 42 cases of IMT of the bladder. ${ }^{7}$ We report a new case of inflammatory myofibroblastic tumour of the bladder, in which the patient presented with gross hematuria. We review the tumour's clinical presentation, diagnosis and pathological features.

\section{Case report}

A previously healthy 23-year-old woman presented with painless gross hematuria in 2 weeks. She had no history of urinary tract infection, calculi, trauma and other urological abnormality. Laboratory studies were normal, except for severe microscopic hematuria. Initial abdominal ultrasound showed a mass on the bladder dome, but the results of intravenous pyelography were normal. Cytological analysis of urine did not show malignant cells. Contrast-enhanced computed tomography $(\mathrm{CT})$ showed a round mass arising from the wall of the bladder dome, and with deep muscle invasion, the mass could be enhanced non-uniformly (Fig. 1). A suspicious pelvic lymph node was observed. Cystoscopy showed a broad-based tumour in the superior wall of the bladder. The tumour was $3 \mathrm{~cm}$ in diameter; it was bleeding and had necrosis on its surface. We decided to perform transurethral resection (TUR) for hemostasis and because we wanted to keep the tumour tissue for pathological examination. Unfortunately, the effect of hemostasis by TUR was not satisfied and severe hematuria induced hypovolemic shock. Open partial cystectomy was performed to remove the tumour in this emergency.

As this is a rare case, our initial diagnosis was carcinoma of urachus due to the tumour's site, so we removed the partial urachus nearby the bladder simultaneously. Although abnormal lymph node was not detected during the operation, bilateral pelvic lymph tissue was biopsied considering the $\mathrm{CT}$ results. The final pathologic diagnosis was inflammatory myofibroblastic tumour of bladder (Fig. 2). The maximum diameter of the tumour was $3 \mathrm{~cm}$ and invasion of muscularis propria was observed (Fig. 3), however, serous membrane of bladder was intact. The necrosis and bleeding were seen in the tumour tissue. There were many ganglion-like cells, spindle cells and epithelioid cells in the lesion. Mitoses were only occasionally found (2-3/10 hpf) (Fig. 4). The results of immunohistochemistry (IHC) examination showed: CD117 (-); DOG-1(-); CD34(-); ALK(+); Galdesmon(-); SMA(+); about $25 \%$ the tumour cells were $\mathrm{Ki}-67$ positive. There was no histologic evidence of extension to the lymph tissue and urachus. 


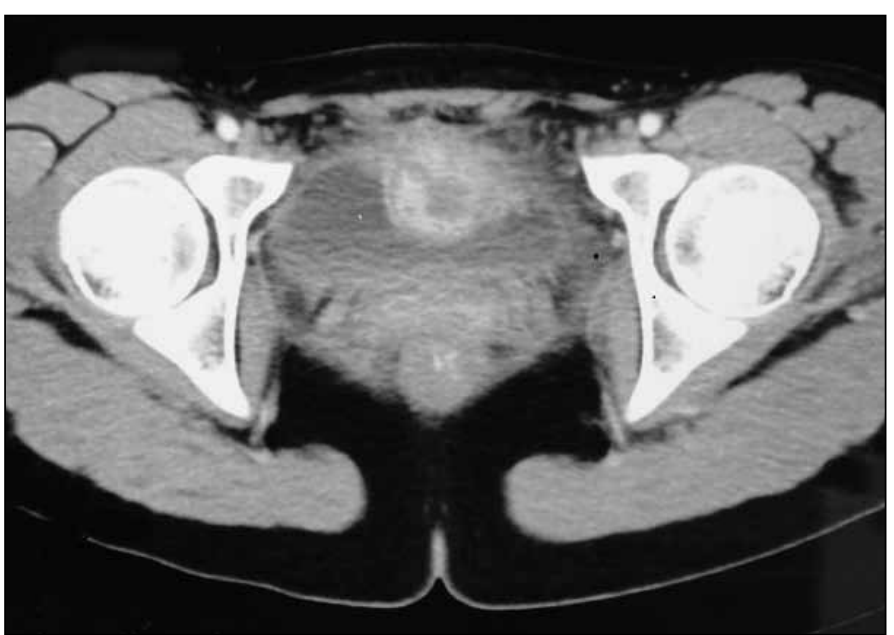

Fig. 1. Contrast-enhanced computed tomography showed a round mass arising from the wall of the bladder dome and with deep muscle invasion, the mass could be enhanced non-uniformly.

\section{Discussion}

IMT is a rare pathologic entity composed of myofibroblasts and an accompanying inflammatory infiltrates. IMT was first recognized in the lung. Although some cases of IMT are considered to represent an inflammatory response to infection, trauma or surgery, ${ }^{8}$ the etiological factors are not clear. We reviewed 17 cases of IMT of the bladder (Table 1); ${ }^{9-20}$ patients' ages ranged from 3 to 72 years (mean 37) and males were represented slightly more than females (ratio 9:8). The most common symptom of IMT is hematuria. The data are consistent with Iczkowski and colleagues. ${ }^{21}$ They researched clinic data of IMT in 36 patients, whose chief complaint was hematuria $(n=27)$. The diagnosis of IMT may remain a dilemma for urologists, radiologists and pathologists. Because the IMT of the bladder has similar clinical

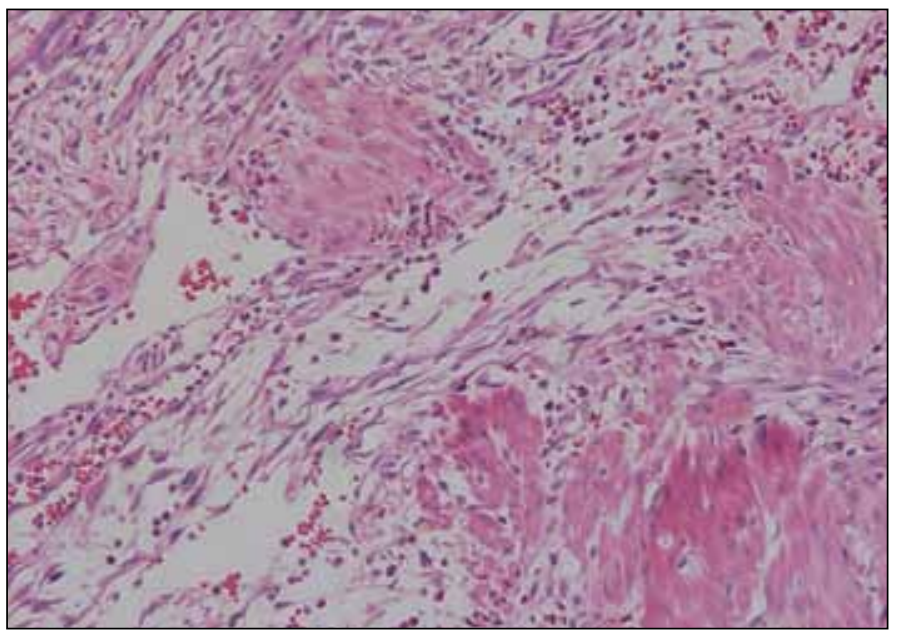

Fig. 3. Image shows the invasion of muscularis propria (hematoxylin and eosin stain, $\times 100)$.

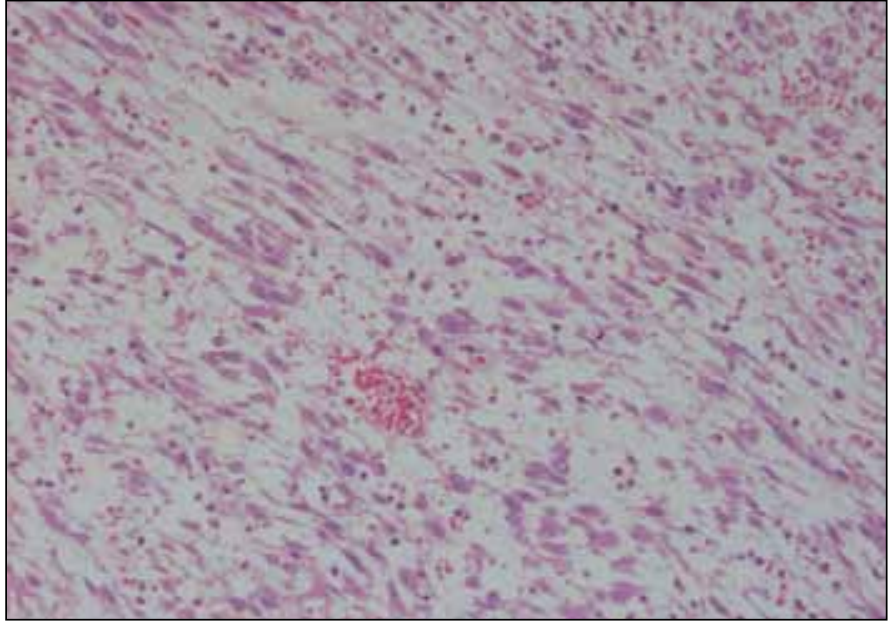

Fig. 2. Inflammatory myofibroblastic tumors cells were spindle to stellate in shape, widely separated or showed a compact fascicular pattern (hematoxylin and eosin stain, $\times 100)$.

features to uroepithelial cancer and it is sometimes aggressive on imaging, this lesion is often mistaken as a malignant process in the diagnostic procedure and during surgery. In our case, according to cystoscopic evaluation and CT results, invasive bladder cancer was established and a radical cystectomy was the next therapeutic option.

The diagnosis of IMT is identified by pathological examination. Immunohistochemical stain can help pathologists confirm the diagnosis. Histologically, the tumour cells were spindle to stellate in shape, widely separated or showed a compact fascicular pattern. They were often mixed inflammatory infiltrates and an irregular meshwork of small dilated vessel. Mitoses were typically scant. ${ }^{15}$ Montgomery and colleagues reviewed a series of IMTs arising in the ureter, bladder and prostate derived primarily from a large consultation practice. ${ }^{22}$ They found necrosis in 14 (30\%) cases.

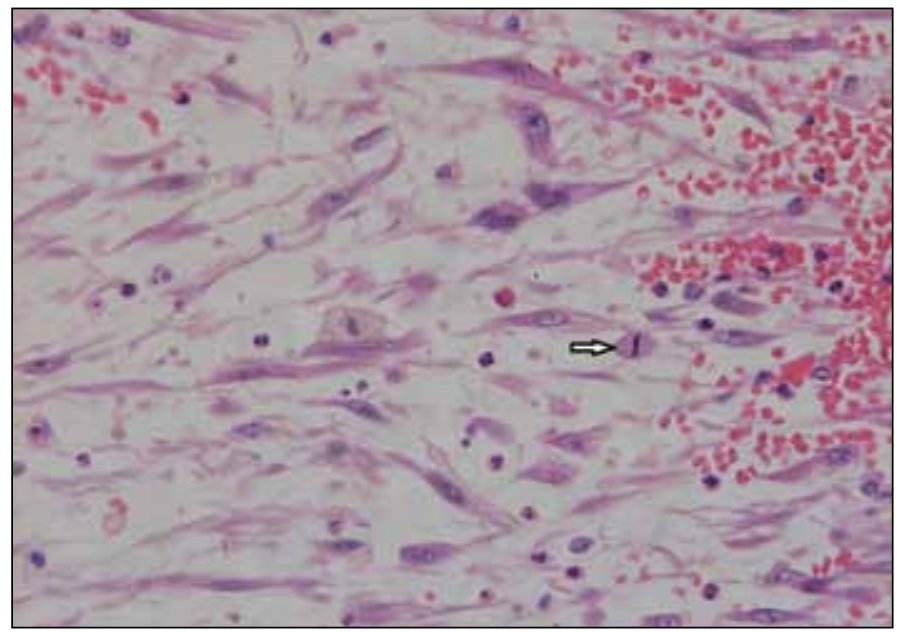

Fig. 4. Image shows typical mitotic figures (white arrow, hematoxylin and eosin stain, $\times 200$ ). 


\begin{tabular}{|c|c|c|c|c|c|c|}
\hline Author & Number & Gender & Age (years) & Country & Symptoms & Treatment \\
\hline Lecuona et al. $^{9}$ & 1 & $\mathrm{M}$ & 3 & South Africa & Hematuria & Partial cystectomy \\
\hline Inoue et al. ${ }^{10}$ & 2 & M & 61 & Japan & Hematuria & TURBT \\
\hline Chatzidarellis et al. ${ }^{11}$ & 3 & M & 58 & Greece & Hematuria & Radical cystectomy \\
\hline Yagnik et al. ${ }^{12}$ & 4 & M & 30 & India & Hematuria & Partial cystectomy \\
\hline Kinoshita et al. ${ }^{13}$ & 5 & $\mathrm{~F}$ & 15 & Japan & Hematuria & TURBT \\
\hline Garrido et al. ${ }^{14}$ & 6 & $\mathrm{~F}$ & 30 & Spain & Recurrent urinary infection & TURBT \\
\hline Sun et al. ${ }^{15}$ & 7 & M & 53 & China & Hematuria & Partial cystectomy \\
\hline Sun et al. ${ }^{15}$ & 8 & $\mathrm{~F}$ & 10 & China & Urodynia, hematuria & Partial cystectomy \\
\hline Sun et al. ${ }^{15}$ & 9 & M & 45 & China & Hematuria & Partial cystectomy \\
\hline Sun et al. ${ }^{15}$ & 10 & M & 48 & China & Dysuria, hematuria & Partial cystectomy \\
\hline Sun et al. ${ }^{15}$ & 11 & $\mathrm{~F}$ & 17 & China & Pelvic pain, hematuria & Partial cystectomy \\
\hline Razi et al. ${ }^{16}$ & 12 & $F$ & 58 & Iran & Dysuria, hematuria & TURBT \\
\hline Razi et al. ${ }^{16}$ & 13 & $\mathrm{~F}$ & 23 & Iran & Pelvic pain, hematuria & TURBT \\
\hline Lantz et al. ${ }^{17}$ & 14 & $F$ & 44 & Canada & Dysuria, hematuria & Partial cystectomy \\
\hline Hayashi et al. ${ }^{18}$ & 15 & M & 72 & Japan & Hematuria & Partial cystectomy \\
\hline Takeshita et al. ${ }^{19}$ & 16 & $\mathrm{~F}$ & 52 & Japan & Urodynia & Partial cystectomy \\
\hline Benchekroun et al. ${ }^{20}$ & 17 & M & 18 & France & Hematuria & Partial cystectomy \\
\hline
\end{tabular}

Invasion of the muscularis propria was found in 19 (41\%). By IHC, lesions at least focally expressed anaplastic lymphoma kinase (ALK) (20/35, 57\%), CAM5.2 (10/15, 67\%), CK18 (6/6, 100\%), actin (23/25, 92\%), desmin (15/19, 79\%), caldesmon $(4 / 7,57 \%$, rare cells), p53 (10/13, 77\%); most lacked S100 (0/14), CD34 (0/13) and CD117 (2/13, 15\%). The histology and immunohistochemistry of our case were consistent with previous studies. However, there was not enough evidence to diagnose sarcoma, as in our case only 2-3/10 hpf typical mitotic figures were found even in most active mitotic area.

The therapy of IMT usually includes TUR, partial cystectomy and radiotherapy. Complete surgical resection is important to avoid local recurrence. ${ }^{16}$ Compared with TUR, partial cystectomy is used for most patients (Table 1). One patient had a radical cystectomy due to the uncertain pathogenesis of the inflammatory myofibroblastic tumour and the rarity of Von Recklinghausen's disease. In our case, the patient finally underwent partial cyctectomy. Considering the muscle invasive feature of IMT, we think the partial cystectomy may be more reliable to avoid tumour residue. If the tumour recurred after endoscopic resection, a partial cystectomy was suggested. In our review of the 17 cases, nearly half of the patients received regular follow-up for at least 6 months, without evidence of local recurrence (data not shown). Iczkowski and colleagues reported no recurrence of inflammatory pseudotumours after TUR or partial cystectomy in 36 patients. ${ }^{21}$ Additionally, Berger and colleagues reported the first case of a bladder inflammatory myofibroblastic tumour that responded to an anti-inflammatory regimen (prednisone and Cox-2 inhibitor) before surgical extirpation. ${ }^{23}$

\section{Conclusion}

IMT is a rare neoplasm with unknown malignant potential. Typical IMTs can be locally aggressive, and may require radical surgical resection, therefore close follow-up is warranted.

Competing interests: None declared.

This paper has been peer-reviewed.

\section{References}

1. Chen CK, Jan Cl, Tsai IS, et al. Inflammatory myofibroblastic tumor of the lung: a case report. J Cardiothorac Surg 2010;5:55. http://dx.doi.org/10.1186/1749-8090-5-55

2. Sari A, Tunakan $M$, Ünsal B, et al. Inflammatory pseudotumor of the liver diagnosed by needle biopsy: report of three cases (one with neuroendocrine tumor of the rectum and lung). Turk J Gastroenterol 2010;21:308-12.

3. Son SB, Heo YS, Shin WW, et al. A case of cutaneous inflammatory myofibroblastic tumor. Ann Dermatol 2010;22:91-5. http://dx.doi.org/10.5021/ad.2010.22.1.91

4. Montgomery EA, Shuster DD, Burkart AL, et al. Inflammatory myofibroblastic tumors of the urinary tract: a clinicopathologic study of 46 cases, including a malignant example inflammatory fibrosarcoma and a subset associated with high-grade urothelial carcinoma. Am I Surg Pathol 2006;30:1502-12. http:// dx.doi.org/10.1097/01.pas.0000213280.35413.1b

5. Tunuguntla $\mathrm{H}$, Mishra A, Jorda $M$, et al. Inflammatory myofibroblastic tumor of the epididymis: case report and review of the literature. Urology 2011;78:183-5. http://dx.doi.org/10.1016/i.urology.2010.09.027

6. Roth JA. Reactive pseudosarcomatous response in urinary bladder. Urology 1980;16:635-7. http:// dx.doi.org/10.1016/0090-4295(80)90578-6

7. Harik LR, Merino C, Coindre JM, et al. Pseudosarcomatous myofibroblastic proliferations of the bladder: a clinicopathologic study of 42 cases. Am J Surg Pathol 2006;30:787-94. htrp://dx.doi.org/10.1097/01. pas.0000208903.46354.6f

8. Sugita R, Saito M, Miura M, et al. Inflammatory pseudotumour of the bladder: CT and MRI findings. $B r$ J Radiol 1999;72:809-11. 
Wei et al.

9. Lecuona AT, Wyk AC, Smit SG, et al. Inflammatory Myofibroblastic Tumor of the Bladder in a 3-Year-old Boy. Urology 2012;79:215-8. http://dx.doi.org/10.1016/i.urology.2011.04.052. Epub 2011 Jul 8.

10. Inoue $\mathrm{T}$, Kinoshita $\mathrm{H}$, Horikoshi $\mathrm{M}$, et al. A case of inflammatory myofibroblastic tumor of the urinary bladder. Hinyokika Kiyo 2011;57:141-5.

11. Chatzidarellis E, Mazaris E, Skolarikos A, et al. Inflammatory Myofibroblastic Bladder Tumor in a Patient with Von Recklinghausen's Syndrome. Case Rep Med 2010;2010. pii: 523964. http://dx.doi. org/10.1155/2010/523964. Epub 2010 Aug 8.

12. Yagnik $V$, Chadha $A$, Chaudhari $S$, et al. Inflammatory myofibroblastic tumor of the urinary bladder. Urol Ann 2010;2:78-9. http://dx.doi.org/10.4103/0974-7796.65106

13. Kinoshita T, Takao T, Nagahara A, et al. Inflammatory myofibroblastic tumor of the bladder: a case report. Hinyokika Kiyo 2008;54:669-72.

14. Garrido Abad P, Coloma del Peso A, Jiménez Gálvez M, et al. Inflammatory myofibroblastic tumor. Case report. Arch Esp Urol 2008;61:62-5.

15. Sun K, Wang ZM, Xu L, et al. Inflammatory myofibroblastic tumor of bladder: a clinicopathologic study of five cases. Zhonghua Bing Li Xue Za Zhi 2007;36:605-8.

16. Razi A, Radmehr A. Inflammatory pseudotumor of bladder: report of 2 cases and review of literature. Urol J 2008;5:62-5

17. Lantz AG, Power NE, Gupta $R$, et al.Inflammatory pseudotumor: a rare cause of hematuria and shock. Urology 2007;70:372.e3-6.
18. Hayashi T, Abe T, Nakayama J, et al. A case of inflammatory myofibroblastic tumor of the bladder. Hinyokika Kiyo 2006;52:955-7.

19. Takeshita H, Kawakami S, Okubo Y, et al. A case of inflammatory myofibroblastic tumor of the urinary bladder finally diagnosed by anaplastic lymphoma kinase (ALK) immunostaining. Hinyokika Kiyo 2006;52:375-8

20. Benchekroun A, el Ali HA, Essayegh $\mathrm{H}$, et al. Inflammatory pseudotumor of the bladder: a new case report. Ann Urol 2003;37:105-7. http://dx.doi.org/10.1016/S0003-4401 (03)00037-8

21. Iczkowski KA, Shanks JH, Gadaleanu V, et al. Inflammatory pseudotumor and sarcoma of urinary bladder: differential diagnosis and outcome in thirty-eight spindle cell neoplasms. Mod Pathol 2001;14:1043-51. http://dx.doi.org/10.1038/modpathol.3880434

22. Montgomery EA, Shuster DD, Burkart AL, et al. Inflammatory myofibroblastic tumors of the urinary tract: a clinicopathologic study of 46 cases, including a malignant example inflammatory fibrosarcoma and a subset associated with high-grade urothelial carcinoma. Am I Surg Pathol 2006;30:1502-12. http:// dx.doi.org/10.1097/01.pas.0000213280.35413.1b

23. Berger A, Kim C, Hagstrom N, et al. Successful preoperative treatment of pediatric bladder inflammatory myofibroblastic tumor with anti-inflammatory therapy. Urology 2007;70:372.e13-5.

Correspondence: Dr. Li Wei, Department of Urology, The People's Hospital of Guangxi Zhuang, Autonomous Region, Nanning, 30021, China; liwei-q@tom.com 